\title{
Time for change? Applying an inductive timeline tool for a retrospective study of disaster recovery in Montserrat, West Indies
}

\begin{abstract}
The recovery process unfolds over a long time and can last for decades, yet most studies of recovery are over short timeframes or represent points in time across the process. Long-term disaster recovery studies are necessary in order to understand the process and the changes that are promoted by disasters over many years. Retrospective methods offer opportunities to gather a dataset of changes over long periods of time, yet concerns with the reliability of participant recall create challenges for research. Retrospective studies need improved data gathering techniques to facilitate reliable recall.

This paper documents the use of an inductive timeline in a retrospective study of disaster recovery for the healthcare system in Montserrat, West Indies. Drawing on creative approaches in the literature we developed a timeline tool for use within focus group settings. We conducted four focus groups with healthcare staff in $2011(n=7, n=8, n=6, n=7)$ to gather retrospective data over the extended period of the eruption of Soufrière Hills Volcano (episodic since 1995).

The approach yielded rich empirical data of changes to the healthcare system observed by the participants over time. Triangulating the results with secondary data (where available) and interviews demonstrated excellent participant recall using this technique. This approach potentially opens-up a field of study in long-term disaster recovery for historical events or cases where poor records have limited their study to date. Further applications could include study of long-term change processes in different social and environmental contexts.
\end{abstract}

Keywords: retrospective method, long-term disaster recovery, change processes, Soufrière Hills Volcano, participatory research. 


\section{Introduction}

Disaster recovery is defined as: 'The restoration, and improvement where appropriate, of facilities, livelihoods and living conditions of disaster-affected communities, including efforts to reduce disaster risk factors' (UNISDR 2009, p. 10). Recovery is understood to be a complex process that is non-linear and multi-dimensional (Olshansky, 2005; Phillips, 2009; Chang, 2010; Tierney \& Oliver-Smith, 2012). Changes are stimulated by disasters, which may be slow or rapid, linear or non-linear, planned or unplanned and may manifest in many aspects across society (Birkmann et al., 2010). Post-disaster changes may be difficult to identify soon after an event and require a long-term view. Recovery processes unfold over a long time and can last decades, yet most studies of recovery are of limited duration or represent points in time across the disaster recovery continuum (Smith \& Birkland, 2012). In order to understand the processes at work studies of recovery need to be viewed over a much longer time-scale (Mitchell, 1996; Cutter et al., 2006; Rubin, 2009; Chang, 2010; Reiss, 2012; Smith \& Birkland, 2012; Rossetto et al., 2014).

The Forensic Investigations of Disasters (FORIN) project (part of the Integrated Research on Disaster Risk (IRDR) Programme) emphasizes the value of longitudinal analysis in providing in-depth understanding of the causal processes underlying disasters (Integrated Research on Disaster Risk, 2011). Longitudinal studies may be prospective (forward-tracking) or retrospective. Challenges for conducting prospective studies include high costs, in terms of both money and time, as well as the loss of participants in follow-up over time (Hass et al., 1977; Berney \& Blane, 2003). Retrospective data remain important in understanding change processes but must contend with issues of reliable participant recall. Creative methodologies are required in order to facilitate the gathering of reliable retrospective data (Berney \& Blane, 2003).

Traditionally used in life course studies, participatory timelines allow documentation and recording of participants' past experiences through time, while simultaneously extending and deepening understanding of the context (Sheridan et al., 2011). Drawing on participatory timeline methods (Bagnoli, 2009; Sheridan et al., 2011), we developed an inductive timeline tool to explore long-term disaster recovery processes. We applied this approach in four focus groups conducted with healthcare staff in Montserrat, West Indies. The approach facilitated retrospective recall of changes to the healthcare system over the long duration of the eruption of Soufrière Hills Volcano (episodic activity since 1995).

The purpose of this paper is to describe the technique and its implementation within this case study context. First, we discuss the case study context and draw on the literature of retrospective methods to develop our approach. Second, we describe the design and implementation of the inductive timeline tool and the logistical considerations for its use. We reflect on the strengths and weaknesses of the approach, and discuss possible applications. Finally, we conclude that extended retrospective studies, which use tools that facilitate reliable recall, have the potential to significantly enhance empirical knowledge of post-disaster change and recovery processes. 


\section{Case study context}

Montserrat is a small British Overseas Territory in the West Indies, with a colonial history and a complex dual government system with a British Governor (appointed by the UK Government) and a locally elected Government of Montserrat (GoM). The sudden onset eruption of the Soufrière Hills Volcano began on 18 July 1995 (Sparks \& Young, 2002). Large-scale evacuations from inhabited areas closest to the volcano ensued. In 1996 the majority of the population, including all the inhabitants of the capital, Plymouth, were permanently relocated further from the volcano (Aspinall et al., 2002). The majority of housing and most of the island's infrastructure had to be relocated and re-established in a rural and little-developed landscape in the north of the island (Clay et al., 1999). Real GDP declined by $44 \%$ between 1994 and 1997 and by early 1998 the population had reduced by about 70\% (Clay et al., 1999; Kokelaar, 2002). Over the years the population increased to reach roughly half of its preeruption size, with the national census recording a population of 4,491 in 2001, and 4,922 in 2011 (Government of Montserrat (GoM), 2001, 2012).

The eruption, which is ongoing, triggered a protracted disaster on the island (Clay et al., 1999; Pattullo, 2000) that has been exacerbated by the dual governance system, large-scale population emigration, and significant economic decline (Clay et al., 1999; Druitt \& Kokelaar, 2002; Wisner et al., 2004; Haynes, 2005; Haynes, 2006; Sword-Daniels et al. 2014). Today ashfalls, acid rain and gases from the volcano affect the relocated population in the north of the island intermittently. The British Government currently supports Montserrat's economy through the Department for International Development (DFID), providing around 60\% of the recurrent budget (Clay et al., 1999; Sword-Daniels, 2014). DFID provided more than $£ 350$ million to support Montserrat during the period 1995-2012 (DFID 2012a). The Montserrat Volcano Observatory (MVO) monitors the volcanic activity on the island, gathers scientific data, and carries out research on the volcano. The Disaster Management Coordination agency (DMCA) is a Government Department that coordinates emergency operations and emergency response by liaising with the various governmental bodies and agencies (e.g. Healthcare, Public Works Department, Fire Search and Rescue, Police). To manage volcanic risk, the island is divided into zones (Figure 2) and a Hazard Level system is used to manage and communicate risk for each zone, which varies depending on the level of volcanic activity (MVO, 2014).

The political, geographic, social and economic context of this small island create a unique set of case study characteristics. Small island contexts are unique, yet they may share vulnerability characteristics that are derived from population demographics, small geographic size, dependence on overseas resources, and limited social and physical infrastructure (Briguglio, 1995; Pelling \& Uitto, 2001). Montserrat provides a geographically-bounded context where access to complex systems such as the healthcare system allows in-depth study of changes over many years since the onset of the eruption. Here, a detailed case study of disaster recovery can be explored in-depth.

The healthcare system underwent significant change after the onset of the eruption. The island's only hospital was relocated from Plymouth to a school in the north of the island. The school building was gradually upgraded and transformed into the current hospital site in St John's (Buffonge, 1999). The number of island clinics (health centres) reduced from 12 to four when the exclusion zone was implemented (Figures 1 and 2), and many experienced healthcare staff emigrated overseas in the first years of the crisis. A recent study documents in detail the consequences of the long-term volcanic 
eruption for the healthcare system in Montserrat (Sword-Daniels, 2014), but today the healthcare system consists of one hospital (secondary care), two elderly care homes (one public, one private), four clinics (primary care) and a headquarters.

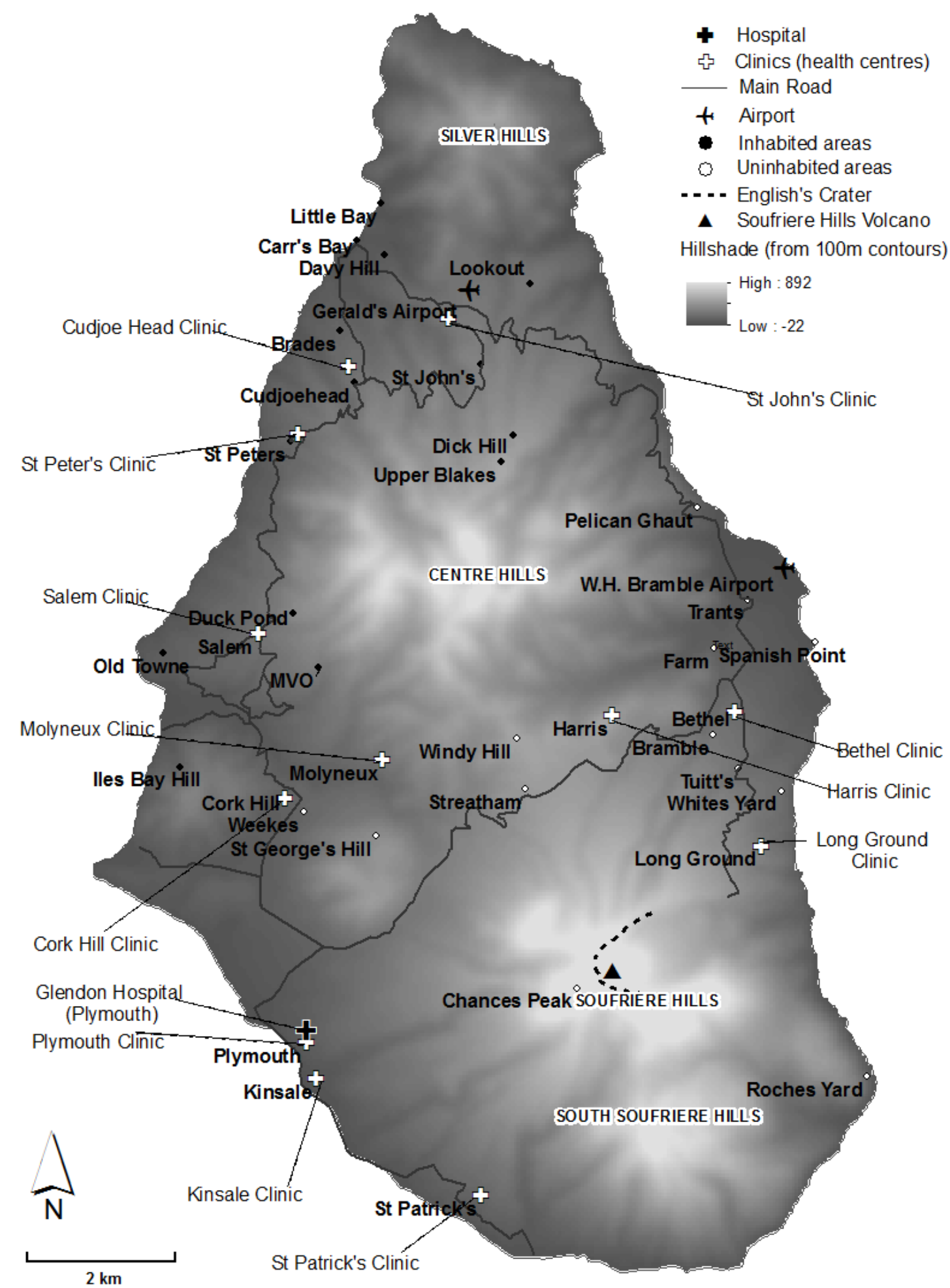

Figure 1 Healthcare facility locations in 1995. Hillshade produced from 100m contour Map (BGS-Government of Montserrat data). 


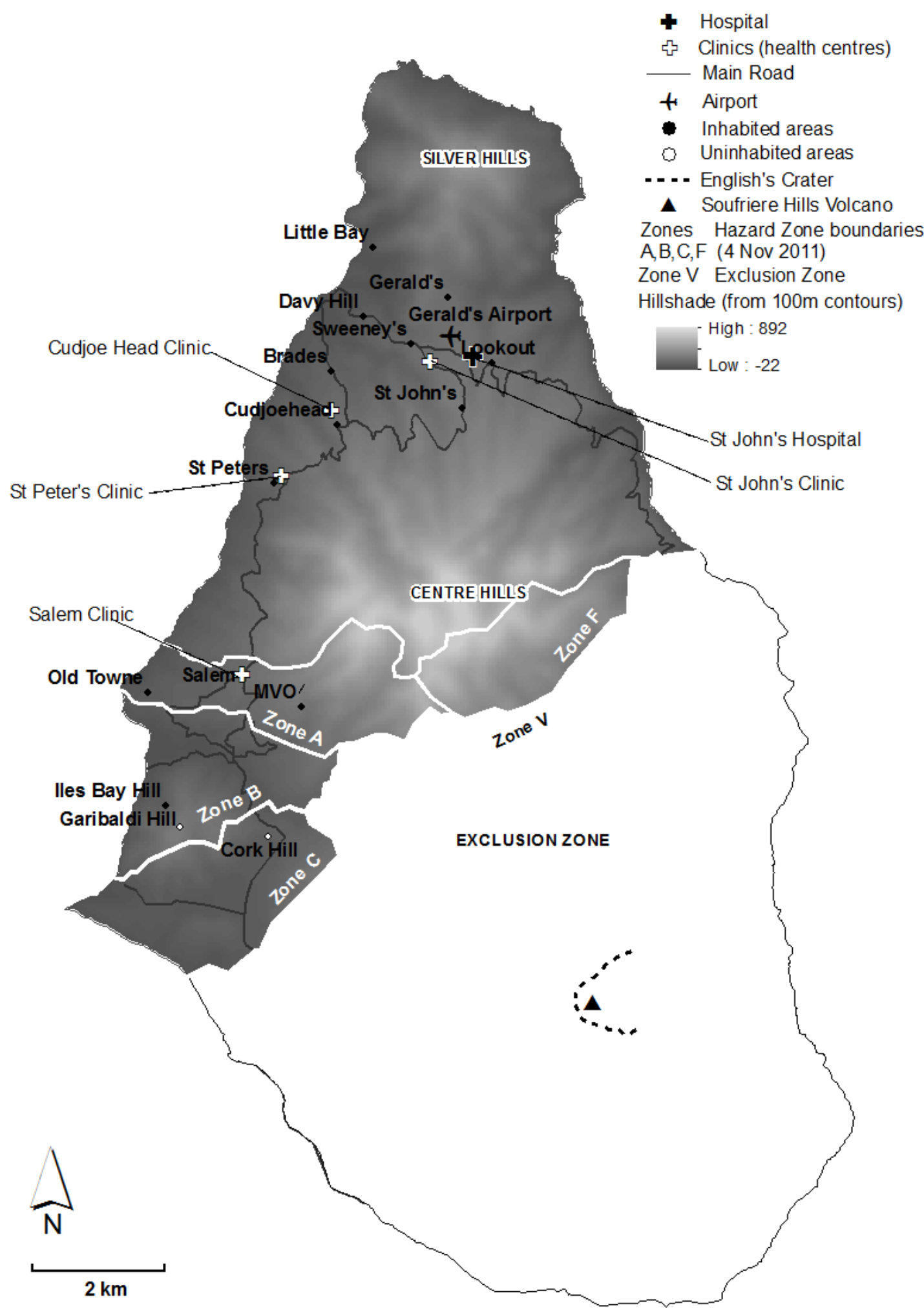

Figure 2 Healthcare facility locations in 2012. Hillshade produced from 100m contour Map (BGS-Government of Montserrat data).

Beyond some initial documentation of change between 1995 and 1999 (Buffonge, 1998; 1999; 2000), there are few records of changes to the healthcare system over time. In this context eliciting empirical 
data from retrospective recall is essential, in order to understand changes over time and build a picture of the recovery process.

An initial interview-based study conducted in 2010 (Sword-Daniels, 2011), elicited rich data on changes to essential services and society, but found that essential service participants were reluctant to assign dates to the changes that they had observed. Participants explained that when they were unsure if a date was correct, they did not wish to mislead the researcher by assigning a date that might be wrong. Dates given with more confidence surrounded significant volcanic events in the period 1995-97 and 2003 (largest dome collapse to date), creating a time dichotomy. A different methodological approach was needed to facilitate participant recall in an environment in which they felt comfortable, and where they could seek validation of their recollections of the type of change and when change occurred.

\section{Retrospective methods}

Retrospective studies of disaster recovery focus mainly on recently-occurring disasters, undertaken within a few years of the disaster event. These have included single case studies (Johnson, 1999), and comparison of several disasters (Rubin, 1985). In an early study of reconstruction after disasters, two historical cases are included (where extensive post-disaster research material was available for analysis) in comparison with two recent disasters (Haas et al., 1977). Yet to date few research studies follow a retrospective approach to gather empirical data of historical cases.

Challenges in using retrospective methods over long periods of time include participant recall, where lapses of memory, simplification of events, and also rationalisation (trying to rationalize or justify behaviours or decisions), self-presentation (participants may try to influence the perception of their image) and attribution (seeking to explain the causes of events) are possible (Wolfe \& Jackson, 1987). Increases in the time since the event, and also short-duration (rather than extended) events, are found to decrease recall accuracy (Cannell et al., 1965). Yet retrospective studies serve to gather rich detail on changes as perceived, framed and expressed by expert informants (Glick et al., 1990). It is therefore important to reduce (albeit not possible to eliminate,) recall bias in retrospective data. This can be achieved through the improvement of data gathering techniques (Freedman, et al., 1988; Berney \& Blane, 2003).

Recall accuracy varies among studies but recall of simple educational, occupational and residential data has been shown to be relatively accurate, even after decades (Thompson, 1988; Berney \& Blane, 2003). Oral history studies show that placing the event in context before eliciting an exact date can aid recall (Berney \& Blane, 2003). Recall may also be improved by having a temporal reference system, and may be aided by significant events where people remember actions or locations associated with particular moments in time (Berney \& Blane, 2003). Pre-constructed timelines are sometimes used as a recall aid to elicit retrospective data and are found to enhance recall accuracy (Van der Vaart \& Glasner, 2007).

There are a variety of methods and tools for eliciting retrospective and longitudinal data, which are discussed in the following sections. These include: oral histories (Powles, 2004; Slim \& Thompson, 1993; Thompson, 1988), event history and life history calendars (Belli et al., 2001; Freedman et al., 
1988), life grids (Berney \& Blane, 2003; Wilson et al., 2007), life mapping (Worth, 2011), and timelines (Bagnoli, 2009; Rubin, 2009; Sheridan et al., 2011). Approaches are grounded in ethnography, epidemiology, psychology, or studies of organisational change and adopt methods for gathering retrospective information that are mainly interview or questionnaire-based. The use of semistructured or open ended questioning allows discussion of events grounded in experiences, and not framed or restricted by a priori themes. Some studies also use multiple participants, which allows improved internal validity by checking accounts against others, resolving discrepancies in face to face discussions (Wolfe \& Jackson, 1987).

Oral testimony and oral history methods are valuable in revealing people's experiences, actions and attitudes, enabling researchers to view events and changes from the perspective of those who are affected by them and involved in them (Thompson, 1988; Slim \& Thompson, 1993; Powles, 2004). These approaches have been used to good effect in several parts of the world to explore how individual disaster events unfolded (Taylor et al., 1995), to understand how people respond and cope in disasters (Stewart et al., 2007) and to capture longer-term processes of environmental and social change under conditions of stress (Cross \& Barker, 1993). Oral accounts can also supplement historical records and improve understanding of causal processes for change over time within specific contexts (Lane, 1997; Daley et al., 2008; Green et al., 2010). For example, seasonal calendars are used to record indigenous knowledge of weather patterns and climate in Australia, to develop an understanding of local environmental indicators for forecasting changes. This approach can inform culturally appropriate adaptation strategies in changing environments (Green et al., 2010).

Event history calendars and life history calendars are used to retrospectively recall a number of different event histories (Freedman et al., 1988). They use thematic and temporal information to aid the organisation of memory for gathering data (Freedman et al., 1988). This is done by eliciting recall of chronological events within one theme (e.g. employment) and then moving on to other themes in an actor's life history (e.g. residence). The approach allows both 'top down' and 'parallel' retrieval, as actors navigate through sequential (chronological) and parallel pathways (different themes) of events to aid recall (Belli, 1998). Event calendars allow a frame of reference, and easily-recalled events may serve to aid more detailed recall of other events in life. Mainly used to recall significant life events (marriage, schooling and employment, serious illnesses), event history calendars are found to delineate high-quality retrospective reports, even over periods of several years. The use of 'landmarks' (significant events) and parallel retrieval are thought to improve recall (Belli, 1998).

Another visual-temporal approach is the life grid method. This allows different events over many decades to be entered into a grid as they are discussed in interview. These may include external, family, residential and occupational events. Each event type is added in separate columns to form a grid. Complete accuracy is not sought initially: the information is re-visited in interview by asking clarifying questions. Developed within health research with participants over the age of 60, the approach shows good recall accuracy over time periods of many decades, when compared with historical archives (Berney \& Blane, 2003). This method has also been used in a study of young people's accounts of parental substance abuse, where the visual approach creates a more relaxed encounter for engagement, supporting young people's narratives (Wilson et al., 2007).

Creative approaches have become increasingly popular in recent years, with the focus on participatory work, visualisation and introducing different ways for participants to express meaning (e.g. Bagnoli, 
2009; Sheridan et al., 2011; Worth, 2011). The increased use of non-verbal, arts-based methods alongside narrative enquiry may allow a more holistic understanding of the meaning of lived experience (Leitch, 2006). Studies of temporality are well suited to visual methods (Worth, 2011). Tools such as timelines allow participants to recall experiences and changes through time: combining visual and narrative approaches (Bagnoli, 2009; Sheridan et al., 2011). For example, the life-mapping technique is centred on recall of 'fateful moments' (significant events) in life. This may be used as a form of participatory diagram, which is used to enable non-verbal communication as an alternative mode of expression and engagement (Worth, 2011). Timelines may also serve as a basis for deeper analysis of causal processes. For example, timelines constructed of significant disasters and their outcomes in the United States are used to explore causal relationships between major events and policy changes (Rubin, 2004).

\section{Designing and implementing an inductive timeline tool}

An inductive timeline tool was developed for use in Montserrat to facilitate long-term retrospective recall. The aim of the study was to understand change and recovery processes within the healthcare system since the onset of the volcanic eruption.

Drawing from the literature, we used a timeline of secondary data as a recall aid (Van der Vaart \& Glasner, 2007). This secondary data timeline included the dates of significant hazard events, and the employment of key public figures - the director of the Montserrat Volcano Observatory (MVO), the Governor, the Premier, and the Disaster Management Coordination Agency (DMCA) director (Figure 3). 


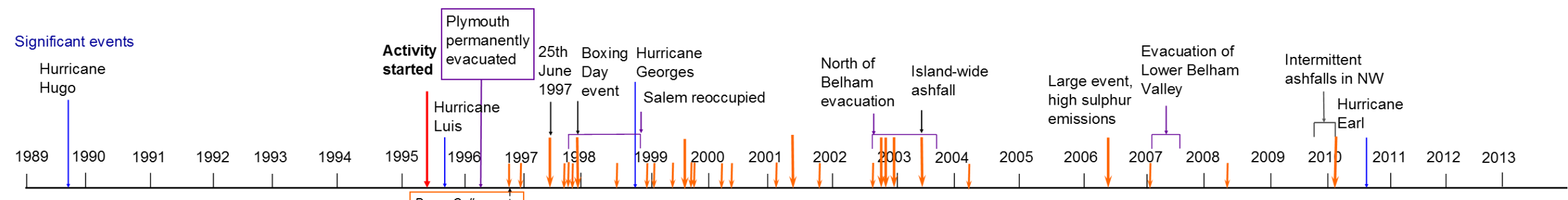

Premier (formerly known as the Chief Minister)

Dome Collapsess.

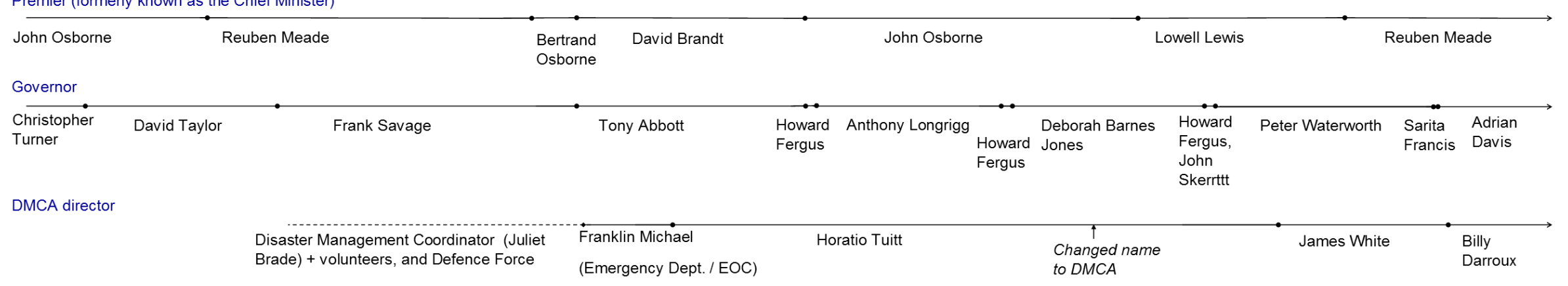

MVO director

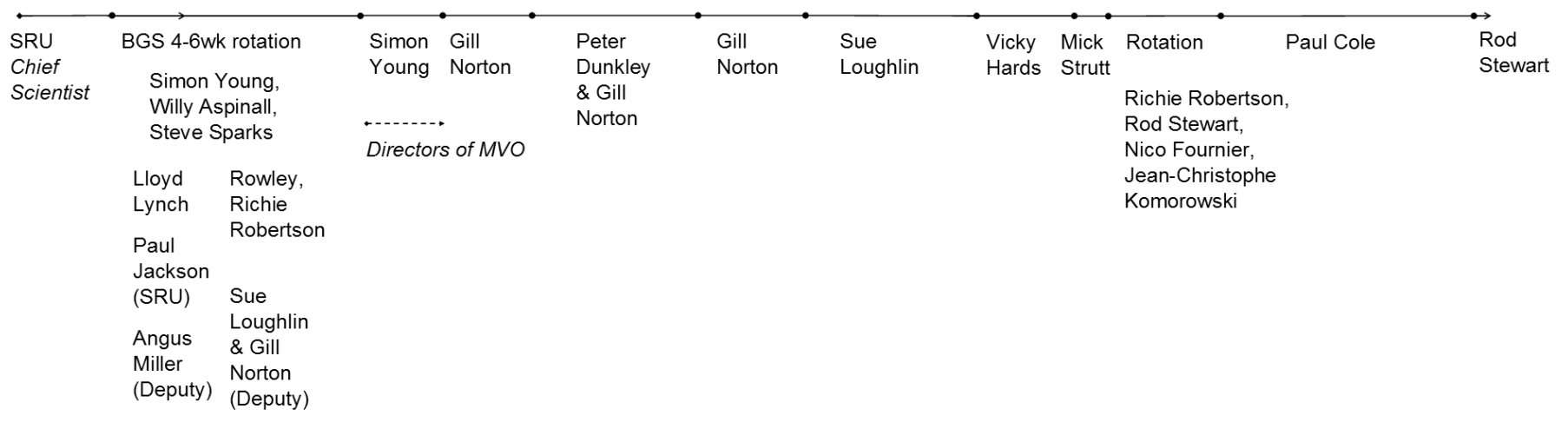

Key of significant events

$\longrightarrow \quad$ Onset of Volcanic activity (18 July 1995)

$\rightarrow \quad$ Hurricanes that have affected the Island

$\rightarrow \quad$ Dome collapse events (longer arrows

Exte larger volume events)

— Period of intermittent ashfalls (2009-10)

Figure 3 Timeline constructed from secondary data of political figures and environmental events, to aid recall. 
International Standard (ISO) AO size $(841 \mathrm{~mm}-1189 \mathrm{~mm})$ sheets of paper were placed on the walls around a room, which were marked with each year above a column. The columns were left blank, to be filled by the participants (Figure 4). The timeline extended from Hurricane Hugo (1989), the last disaster preceding the eruption in 1995, up until the time of the data-collection (2011). Several sheets were needed to cover the extended time period, allowing enough room for any recalled changes to be added. A final column was marked 'future', to include any upcoming or planned changes and any future disaster risk reduction ideas that arose during the task.

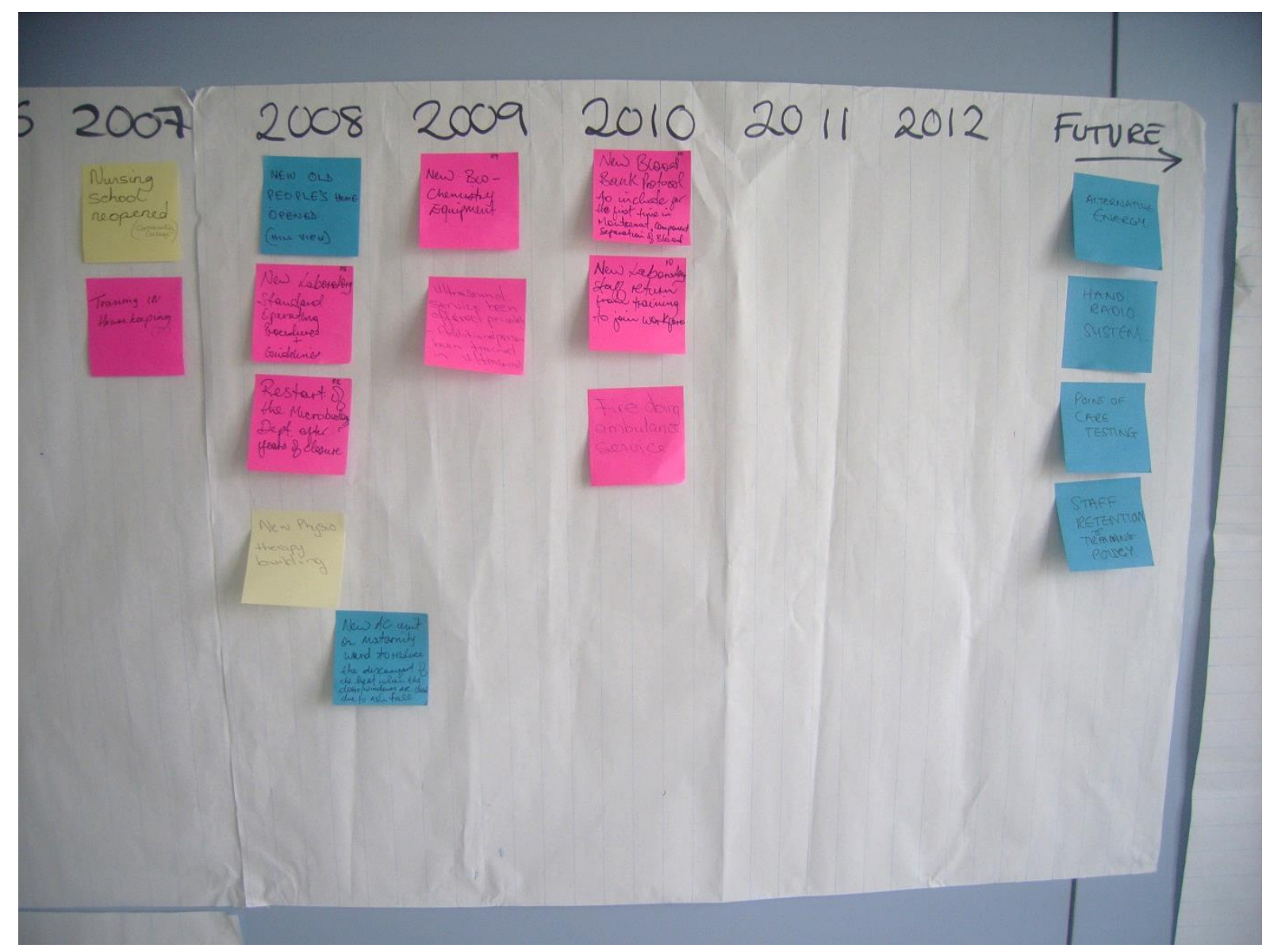

Figure 4 Photograph of a partially-completed section of the inductive timeline tool.

The research design included a purposive sample of experienced staff, preferably working in the healthcare system before the onset of the eruption, in order to discuss and delineate changes over time. However, at the clinics (primary healthcare), the healthcare coordinator asked the researcher whether some junior staff could also be included along with the long-serving employees. This would allow junior nurses to learn from the experienced nurses and gain a better understanding of the changes to the healthcare system since the eruption began. The groups were therefore designed to have mixed experience levels, to incorporate this aspect of learning for the nurses.

Groups of co-workers from primary and secondary healthcare were created, so that the groups knew each other. In this context, familiarity enabled them to speak freely about their department or specialist field and interact in a more natural way. To avoid obvious power differentials, healthcare managers from health headquarters (rather than within the clinic or hospital setting) participated in individual interviews, rather than in a group setting. Rules were set at the start of discussion to try to reduce individual dominance and promote views from all staff, creating a safe environment to talk. 
A range of healthcare roles were included within the groups, to allow broader discussion of issues and changes across the healthcare system (e.g. nurses, specialists, technicians, cleaning and maintenance staff). This allowed wider understanding of different aspects of change, and facilitated cross-sector knowledge exchange and learning.

Four focus groups were conducted, two with clinic staff and two with hospital staff (Table 1). All four groups were conducted within a six week period, between October and November 2011. The high proportion of female participants is representative of the composition of healthcare workers on the island (for example, all clinic staff are female).

Table 1 Relevant information about the focus group participants.

\begin{tabular}{|l|c|c|c|c|c|}
\hline \multicolumn{1}{|c|}{ Focus Group } & $\begin{array}{c}\text { No. of } \\
\text { participants }\end{array}$ & Male & Female & $\begin{array}{c}\text { No. Living on } \\
\text { Montserrat pre-1995 }\end{array}$ & $\begin{array}{c}\text { No. moved to } \\
\text { Montserrat after } \\
1995\end{array}$ \\
\hline Clinic group 1 & 7 & 0 & 7 & 3 & 4 \\
\hline Clinic group 2 & 8 & 0 & 8 & 3 & 5 \\
\hline Hospital group 1 & 6 & 1 & 5 & 3 & 3 \\
\hline Hospital group 2 & 7 & 0 & 7 & 3 & 4 \\
\hline Total participants & 28 & 1 & 27 & $12(43 \%)$ & $16(57 \%)$ \\
\hline
\end{tabular}

At the start of each focus group meeting, the aims of the research and focus group rules and were discussed, and consent was sought for participation and digital recording. The approach began with a focus group discussion about the healthcare system in the volcanic context, and the changes observed over time. Discussion topics included:

- Description of Montserrat's healthcare system before the eruption started

- Description of the healthcare system now

- Overall changes to the healthcare system

- Experiences of eruptions and the effects of volcanic activity at work

- Responses to volcanic activity and ways of reducing effects

This set the context for the inductive timeline task. The focus group discussion was followed by a workshop-style task where the timeline was filled with recalled changes by the participants, who wrote aspects of change on sticky notes and placed them in the column representing the year of change (on the $\mathrm{AO}$ sheet). This created a timeline of change for the healthcare system. Parallel and sequential retrieval (Belli, 1998) were sought by discussing three different themes of change within the healthcare system over time. The themes, which were intended to aid recall, rather than as a final coding scheme, included:

- Physical changes to buildings and infrastructure

- Resource changes in: staffing, equipment and training

- Changes made to respond or reduce the effects of volcanic activity

Each type of change was associated with a different colour sticky note (e.g. yellow for physical changes, pink for resource changes, and blue for volcanic risk reduction). When there appeared to be no more changes for one aspect, the next topic became the focus of conversation. The process prompted much discussion and deliberation about dates, and eventual delineation of changes to the 
satisfaction of the group. This was markedly different to the response in interview in 2010, and elicited a timeline that included a wide variety of changes to the healthcare system over time. Photographs of the timeline taken at the end of the group work allowed creation of a replica electronic copy, which was emailed to the participants after each of the groups.

Focus groups were paired, with the two clinic groups forming one pair, and the two hospital groups forming the other. Timelines were constructed by the first group, and the second group then validated this and changed the dates of events where necessary. The second group then went on to add more data where they could think of additional changes.

The inductive data from all four focus groups were combined to generate a timeline of change for the healthcare sector over the long duration of the eruption. The recalled changes were triangulated with the following secondary documents: Government of Montserrat (GoM) budget speeches (GoM, 2004; 2005; 2007; 2008; 2009; 2010; 2013), Department for International Development (DFID) records (DFID, 2012a; 2012b; 2012c), technical literature (Wason, 1994; PAHO, 2007), and books chronicling events at the time (Buffonge, 1998; 1999; 2000). Triangulation revealed just four discrepancies in timeframes (by one year) between group recall and the secondary data sources across the multiple aspects of change recalled. The final timeline is shown in Figure 5. 


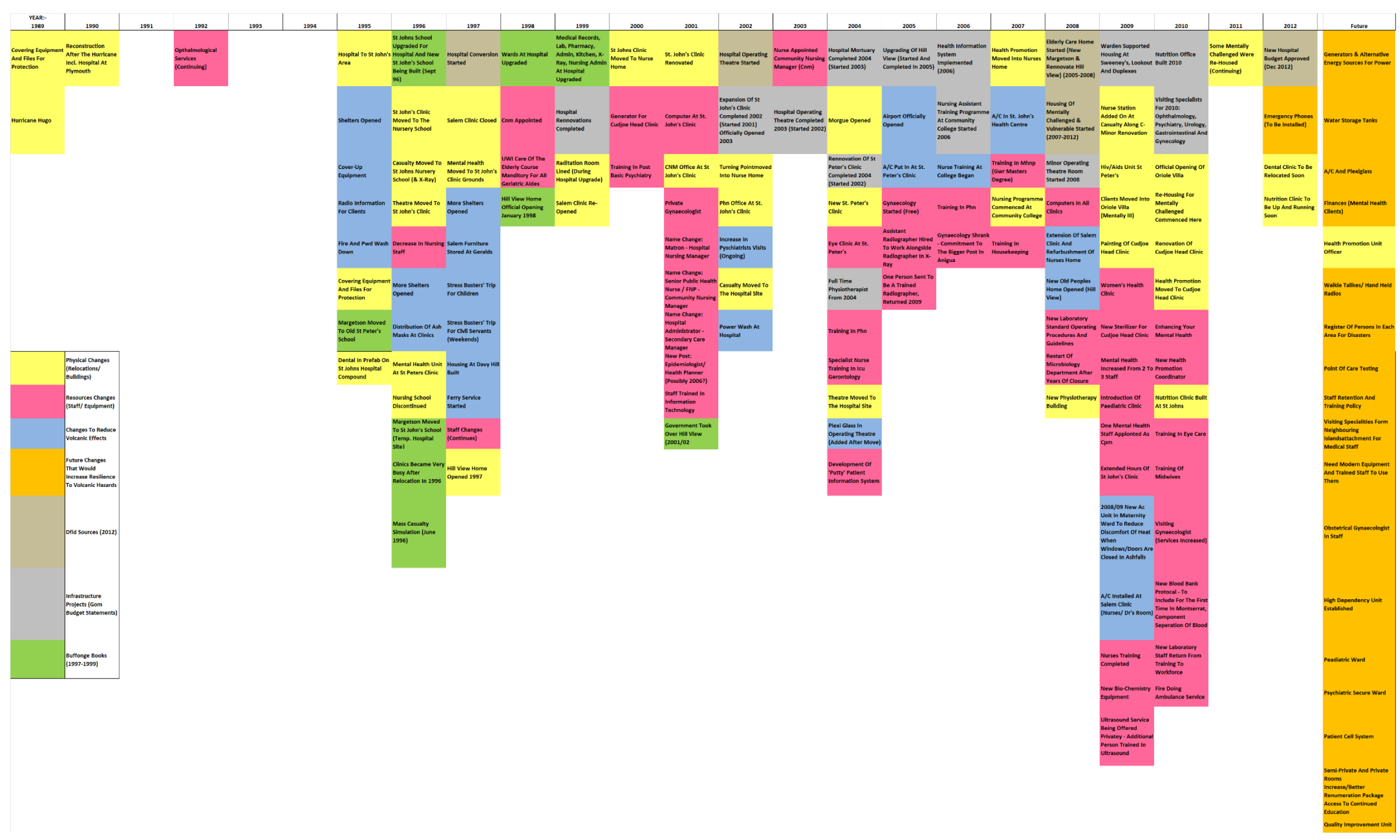

Figure 5 the final timeline. This combines the recalled changes from the participants of all four focus groups (yellow, pink, blue, orange), and secondary data sources used for validation (green, grey, brown). 
A return fieldtrip in 2012, one year after data collection, allowed feedback in person and dissemination of hard copies of the final (combined) timeline. This provided a chronological record to document change in the healthcare system, to share results and to help to retain the institutional memory for the sector. Different types of post-disaster change, and when they occurred, could be identified from the timeline. Analysis of the empirical findings - the types of changes and risk reduction approaches employed in Montserrat - is beyond the scope of this paper. An analysis of the data derived from this retrospective technique unpacks long-term change and recovery processes within the healthcare system in Montserrat, and provides a detailed analysis of long-term disaster recovery (Sword-Daniels et al., n.d. in review).

\section{Reflections on the method}

A critical consideration in the study of long-term recovery is the timing of research. Research conducted a long time after personal experience of a traumatic event allows discussion in a reflective, less emotive way. For example, in Montserrat the deaths from pyroclastic flows in the exclusion zone in 1997 are deeply felt (Loughlin et al., 2002). It is essential that the researcher is aware of the past, and that the ethical implications, appropriateness and timing of discussing event histories are considered before research is undertaken. A tension exists between this, and the turnover and retirement of staff who have experienced significant change during their years of service. At the time of data collection in 2011, many staff were close to retirement age. In this study just 12 of the 28 participants in focus groups were living on Montserrat before the onset of the eruption in 1995. Undertaking research just a few years later may have resulted in loss of institutional memory through retirement, in addition to that lost through emigration over the years of the disaster. Participants seemed to engage with, and enjoy the approach. Feedback was positive, especially from the longestserving staff who reflected on the experience,

'[it was] nice to reflect on the past and how far we've come' (focus group participant)

\subsection{Access, incentives, and logistical considerations}

Initial meetings with key contacts within the hospital and the clinics allowed discussions about the purpose of the research, and the intended format of the group work. These participants were encouraged to raise any of their own desired outcomes from the work, which could then be incorporated within the design. The key contacts voluntarily took on coordinating roles, and provided advice about the timing, location and required incentives for staff participation. Healthcare staff have busy work schedules and may need to respond to emergencies at any time. They needed to be able to return to work quickly as and when necessary. The time of day and location of conducting groups are therefore critical considerations in order to facilitate attendance. Working with the coordinators allowed convenient timings for the staff (afternoons, to avoid busy morning clinics), appropriate locations to be chosen (held on site at the clinics or the hospital), and the coordinator was able to form groups of staff to be included in the groups. Incentives were not needed, although the researcher provided refreshments and homemade cake for the participants. Overall there was a high acceptance rate from the purposive sample of focus group participants, which is considered to create a 
representative data set. Self-selection in focus groups caused by non-attendance of invited participants was very low (George \& Bennett, 2005). Attendance was high overall and greatly enabled by having coordinators placed within the hospital and the clinics, who were able to bring colleagues together for the discussions.

Logistically it took three weeks in the field to organise the first focus group. This time period involved building relationships with healthcare contacts through meetings, as well as setting up appropriate times for the focus groups, allowing time for organisation. Hospital groups took longer to organise due to shift schedules and the busy roles of many staff. One group was also cancelled due to emergency response requirements on the day of the group, and re-scheduled for a later date. It was important to be flexible and re-arrange groups as necessary when unforeseen events occurred.

\subsection{Eliciting reliable recall: strengths and weaknesses of the approach}

The application of the timeline tool within a focus group setting was useful. Benefits included:

- Initial discussion of the event history in a focus group setting allowed framing of the topic around the changes observed over time, before changes were added to the timeline. Participants were encouraged to speak from their own experiences; providing a framework for delineating changes as experienced by those within the system. In this study the themes of change were used as a basis for framing discussion, but could also be used for data analysis.

- A group setting served to relieve pressure on individual recall, and allowed discrepancies to be resolved face-to-face, increasing internal validity.

- Group discussion provided rich narratives about what was happening at the time; providing detail about interrelated aspects of change (parallel retrieval). As the participants discussed and delineated the dates of change, the context and conditions under which change occurred emerged.

- The workshop-style setting for inductive timeline task allowed participants to discuss freely amongst themselves, and to use their own way of deriving dates. This also allowed participants to move around the room, relieving the intensity of group work, and providing a forum for less dominant participants to contribute.

- The timeline altered the interaction from an oral to a visual and more creative mode. This provided a different form of engagement with the topic.

During the inductive timeline task, a few small groups of individuals formed spontaneously to focus on their years of experience with similarly-experienced colleague(s). Conversation yielded robust discussion of dates, and debate surrounding them, and many aspects of work and life were used to delineate correct dates. Data is therefore considered reliable. Timelines were double-checked by the paired group, so any changes or corrections could be made. Two changes were made by the second focus groups in the pair by \pm one year each, demonstrating overall data reliability, but also participant's willingness to correct errors made by other groups. Further aspects of change were then included. The secondary data timeline (constructed as a recall aid) was used infrequently, as 
participants mainly delineated dates through employment history (when staff came or left the healthcare system), or personal life events.

The approach was intensive and it took a relatively long time to work through the focus group discussions and then the timeline task. The first group took three hours; this was considered too long and was shortened to two hours for the following groups. The length of time for each group meant that a break, and a change of mode (from focus group discussion to workshop-style visual timeline) was necessary to combat fatigue. This was also a labour-intensive approach: it took time to organise in the field and rescheduling was also required. This is a particular challenge in the case of healthcare staff, where emergencies may arise on the day and cause cancellation.

The resolution of specific dates is limited using this approach, as changes were recalled only on an annual basis. For this research design, to cover nearly two decades where there are few existing records of impacts and changes, accuracy at the level of 'years' was considered adequate. It is unlikely that resolution could be increased over such long time periods of recall, other than for very specific events, such as the date of a particular eruption or the start of employment. Such specific dates were sometimes recalled by individuals within the groups, often as a starting point for more detailed narrative.

There is limited data with which to triangulate the recalled changes, yet where data are available only four discrepancies by \pm 1 year were identified between recalled and documented data. This reflects a high level of accuracy in participant recall using this approach. Validation is further challenged by discrepancies in documented sources of information in GoM and DFID records, where projects are listed within a particular year (probably for budgetary spending) when in fact the change was implemented, or the facility opened for use, in the following year. For example, DFID list the new hospital refurbishment as commencing in 2012, but had not started by 2013 (DFID, 2012b). Yet the intention was not to test participant recall but to elicit a record of changes as experienced by the participants within the healthcare system.

In cases where data is sparse, the inductive timeline can be a useful method for gathering data about changes, as well as contextual information of the drivers and barriers for change. In this context, group discussions overcame the cultural reluctance to recall dates for known changes. The group dynamic provided an environment that facilitated interaction, debate and eventual agreement. The benefits of discussing and sharing experiences, and learning amongst a group of colleagues were evident both in the co-design before the group work, and in the positive feedback afterwards. The method promoted mutual learning and understanding between researcher and participants and participation in focus group design, data-collection and later feedback allowed good relationships to be formed between the researcher and participants and promoted engagement over a longer timeframe. The timeline output provided a long-term record of change for the healthcare system, useful in this context where the long-timeframes and rapid social demographic change have reduced institutional memory. Having a future section on the timeline also allowed learning to be captured for future wants and needs of those within the healthcare system. This allowed identification of positive steps for the future and ideas for risk reduction that could be developed into action plans by the participants, should they wish to act on the areas identified for improvement. 


\section{Concluding remarks}

This study outlines a creative research method using an inductive timeline that is both interactive and visual, and which elicits accurate participant recall. The ability to derive empirical retrospective data in a reliable way potentially opens-up a field of study in long-term disaster recovery for historical events, or cases where poor records have limited their study to-date. Each case study is unique, and recoveries will be different, yet this retrospective method provides a viable approach for gathering data in different contexts. By exploring post-disaster change in a wide variety of historical cases, a rich picture of the influences on long-term recovery can be developed. Due to some common characteristics of small islands states, studies in other island contexts may provide comparable empirical cases of recoveries.

This method also has potential applicability beyond geophysical hazards, as the approach allows a far greater understanding of change and recovery dynamics that could be meaningfully explored within a wide variety of cases and contexts. Further research could explore applications of this approach beyond the field of disaster recovery, to facilitate recall of changes and adaptations over time in contexts of environmental change. This may be a useful tool for understanding a broad range of change processes in many different social and environmental contexts.

\section{Acknowledgements}

We are indebted to all of the people who participated in this research in Montserrat; both interviewees and others who interacted with the researcher in the field, and who gave generously of their time and contributed to this research. The support of Paul Cole and the Montserrat Volcano Observatory staff was also invaluable during fieldwork. We would like to thank EPSRC for funding this research through the Centre for Urban Sustainability and Resilience at University College London, and the British Geological Survey BUFI fund for funding the fieldwork to undertake this research. Professor Tiziana Rossetto, Professor David Johnston, Dr Thomas Wilson and Dr Susanne Sargeant provided intellectual contributions during this research, which we gratefully acknowledge. We are grateful to the British Geological Survey and the Strengthening Resilience in Volcanic Areas (STREVA) project for support during the writing of this paper.

\section{References}

Aspinall, W. P., Loughlin, S. C., Michael, F. V, Miller, A. D., Norton, G. E., Rowley, K. C., Sparks, R. S. J., Young, S. R. (2002). The Montserrat Volcano Observatory: its evolution, organisation, role and activities. In T. H. Druitt \& B. P. Kokelaar (Eds.), The eruption of Soufrière Hills Volcano, Montserrat from 1995 to 1999 (Vol. 21, pp. 71-91). London: Geological Society, London, Memoirs 2002.

Bagnoli, A. (2009). Beyond the standard interview: the use of graphic elicitation and arts-based methods. Qualitative Research, 9(5), 547-570. doi:10.1177/1468794109343625 
Belli, R. F. (1998). The structure of autobiographical memory and the event history calendar: potential improvements in the quality of retrospective reports in surveys. Memory (Hove, England), 6(4), 383406. doi:10.1080/741942610

Belli, R. F., Shay, W. L., Stafford, F. P. (2001). Event History Calendars and Question List Surveys: a direct comparison of interviewing methods. Public Opinion Quarterly, 65, 45-74.

Berney, L., Blane, D. (2003). The Lifegrid Method of Collecting Retrospective Information from People at Older Ages. Research Policy and Planning, 21(2), 13-22.

Birkmann, J., Buckle, P., Jaeger, J., Pelling, M., Setiadi, N., Garschagen, M., ... Kropp, J. (2010). Extreme events and disasters: a window of opportunity for change? Analysis of organizational, institutional and political changes, formal and informal responses after mega-disasters. Natural Hazards, 55, 637-655.

Briguglio, L. (1995). Small island developing states and their economic vulnerabilities. World Development, 23(9), 1615-1632.

Buffonge, C. (1998). Volcano! Book 3: events in Montserrat during 1997 (p. 141). Montserrat: Ideal Printers.

Buffonge, C. (1999). Volcano! Books 1 and 2 combined edition: a chronicle of Montserrat's volcanic experience during 1995 and 1996 (p. 91). Montserrat: Ideal Printers.

Buffonge, C. (2000). Volcano! Book 41998 and 1999: Montserrat looks to the future and the road to recovery (p. 181). Montserrat: Montserrat Printing and Publishing.

Cannell, C. F., Fisher, G. Bakker, T. (1965). Reporting of Hospitalization in the Health Interview Survey. In Vital and Health Statistics (PHS Public.). Washington DC.

Chang, S. E. (2010). Urban disaster recovery: a measurement framework and its application to the 1995 Kobe earthquake. Disasters, 34(2), 303-327.

Clay, E., Barrow, C., Benson, C., Dempster, J., Kokelaar, P., Pillai, N., \& Seaman, J. (1999). An Evaluation of HMG's Response to the Montserrat Volcanic Emergency. Volume 1 (Vol. Evaluation, pp. 1-105). Department for International Development.

Cross, N. Barker, R. (Eds.). (1993). At the desert's edge: oral histories from the Sahel. London: Panos Publications.

Cutter, S. L., Emrich, C. T., Mitchell, T., Boruff, B. J., Gall, M., Schmidtlein, M. C., ... Melton, G. (2006). The long road home: race, class, and recovery from Hurricane Katrina. Environment, 48(2), 10-21.

Daley, B., Griggs, P., Marsh, H. (2008). Reconstructing reefs: qualitative research and the environmental history of the Great Barrier Reef, Australia. Qualitative Research, 8(5), 584-615. doi:10.1177/1468794108093896

Department for International Development (DfID). (2012a). Montserrat - a British Overseas Territory: Briefing note. 
Department for International Development (DfID). (2012b). Montserrat Programme: key capital projects from 2001.

Department for International Development (DfID). (2012c). Timeline showing key Montserrat capital projects: start dates.

Druitt, T. H., Kokelaar, B. P. (2002). The Eruption of Soufriere Hills Volcano, Montserrat, from 1995 to 1999. In The eruption of Soufriere Hills Volcano, Montserrat from 1995 to 1999 (Vol. 21). London: Geological Society, London, Memoirs 2002.

Freedman, D., Thornton, A., Camburn, D., Alwin, D., Young-DeMarco, L. (1988). The life history calendar: a technique for collecting retrospective data. Sociological Methodology, 18(1988), 37-68.

George, A. L., Bennett, A. (2005). Case studies and theory development in the social sciences (pp. 1331). Cambridge, Massachusetts: MIT Press.

Glick, W. H., Huber, G. P., Miller, C. C., Doty, D. H., Sutcliffe, K. M. (1990). Studying Changes in Organizational Design and Effectiveness: Retrospective Event Histories and Periodic Assessments. Organization Science, 1(3), 293-312.

Government of Montserrat (GoM). (2001). 2001 population and housing census (pp. 1-27). Montserrat: Statistics Department, Ministry of Finance and Economic Development. Government of Montserrat (GoM). (2004). Budget Speech 2004 (pp. 1-30). Montserrat: Ministry of Finance, Economic Development and Trade.

Government of Montserrat (GoM). (2005). Budget Statement (pp. 1-27). Montserrat: Ministry of Finance, Economic Development and Trade.

Government of Montserrat (GoM). (2007). Budget Statement (pp. 1-47). Montserrat: Ministry of Finance, Economic Development and Trade.

Government of Montserrat (GoM). (2008). Budget Statement (pp. 1-29). Montserrat: Ministry of Finance, Economic Development and Trade.

Government of Montserrat (GoM). (2009). Laws of Montserrat. 2008 revised edition: Volumes 1 to 12 (pp. 1-114). Montserrat: Attorney General's Chambers.

Government of Montserrat (GoM). (2010). Montserrat Sustainable Development Plan 2008-2020 (pp. 1-150). Montserrat: Ministry of Economic Development and Trade.

Government of Montserrat (GoM). (2012). Census 2011: Montserrat at a glance (pp. 1-23). Montserrat: Statistics Department, Ministry of Finance and Economic Management.

Government of Montserrat (GoM). (2013). Budget Statement 2013/14 (pp. 1-24). Montserrat: Ministry of Finance and Economic Management.

Green, D., Billy, J., \& Tapim, A. (2010). Indigenous Australians' knowledge of weather and climate. Climatic Change, 100(2), 337-354. doi:10.1007/s10584-010-9803-z 
Haas, E. J., Kates, R. W., Bowden, M. J. (1977). Reconstruction following disaster (p. 331). Cambridge, Massachusetts: MIT Press.

Haynes, K. (2005). Exploring the communication of risk during a volcanic crisis: A case study of Montserrat, WI. (September).

Haynes, K. (2006). Volcanic island in crisis: investigating environmental uncertainty and the complexities it brings. The Australian Journal of Emergency Management, 21(4), 21-28.

Integrated Research on Disaster Risk, 2011. Forensic Investigations of Disasters: The FORIN Project (pp. 1-32). Beijing: Integrated Research on Disaster Risk.

Johnson, L. (1999). Empowering Local Governments in Disaster Recovery Management: Lessons from Watsonville and Oakland in Recovering from the 1989 Loma Prieta Earthquake and Other Recent Disasters. In: Earthquake Engineering Research Institute, Lessons Learned Over Time Volume I (pp. 4184). Oakland, California: Earthquake Engineering Research Institute.

Kokelaar, B. P. (2002). Setting, chronology and consequences of the eruption of Soufriere Hills Volcano, Montserrat (1995-1999). In T. H. Druitt \& B. P. Kokelaar (Eds.), The eruption of Soufrière Hills Volcano, Montserrat from 1995 to 1999 (Vol. 21, pp. 1-43). London: Geological Society, London, Memoirs 2002. doi:10.1144/GSL.MEM.2002.021.01.02

Lane, R. (1997). Oral Histories and Scientific Knowledge in Understanding Environmental Change: a case study in the Tumut Region, NSW. Australian Geographical Studies, 35(2), 195-205. doi:10.1111/1467-8470.00019

Leitch, R. (2006). Limitations of language: developing arts-based creative narrative in the stories of teachers' identities. Teachers and Teaching: Theory and Practice, 12(5), 549-569.

Loughlin, S. C., Baxter, P. J., Aspinall, W. P., Darroux, B., Harford, C. L., Miller, A. D. (2002). Eyewitness accounts of the 25 June 1997 pyroclastic flows and surges at Soufriere Hills Volcano, Montserrat, and implications for disaster mitigation. In T. H. Druitt \& B. P. Kokelaar (Eds.), The eruption of Soufrière Hills Volcano, Montserrat from 1995 to 1999 (Vol. 21, pp. 211-230). London: Geological Society, London, Memoirs 2002.

Mitchell, J. K. (1996). The long road to recovery: community responses to industrial disaster (pp. 1307). Tokyo, Japan: United Nations University Press.

Montserrat Volcano Observatory (MVO). (2014). http://www.mvo.ms/ [Accessed 16/12/2014].

Olshansky, R. B. (2005). How do communities recovery from disaster? A review of current knowledge and an agenda for future research. In 46th Annual Conference of the Association of Collegiate Schools of Planning (pp. 1-19).

Pan American Health Organisation. (2007). Montserrat. In Health in the Americas Volume II - Countries (pp. 486-493). Pan American Health Organisation.

Pattullo, P. (2000). Fire from the mountain: the tragedy of Montserrat and the betrayal of its people (p. 217). London, UK: Constable. 
Pelling, M., Uitto, J. I. (2001). Small island developing states: natural disaster vulnerability and global change. Environmental Hazards, 3, 49-62.

Phillips, B. D. (2009). Disaster Recovery (p. 521). Boca Raton: CRC Press.

Powles, J. (2004). Life History and Personal Narrative: Theoretical and methodological Issues relevant to research and evaluation in refugee contexts (No. 106).

Reiss, C. L. (2012). Introduction to the Special Issue on Disaster Recovery. International Journal of Mass Emergencies and Disasters, 30 (2), 120-122.

Rossetto, T., T. Rossetto - D. D’Ayala, D., Gori, F., Persio, R., Han, J., Novelli, V., Wilkinson, S. M., Alexander, D., Hill, M., Stephens, S., Kontoe, S., Elia, G., Verrucci, E., Vicini, A., Shelley, W., FoulserPiggott, R. (2014). The value of multiple earthquake missions: the EEFIT L'Aquila Earthquake experience. Bulletin of Earthquake Engineering, 12, 277-305.

Rubin, C. A. (1985). The community recovery process in the United States after a major natural disaster. International Journal of Mass Emergencies and Disasters, 9-28.

Rubin, C. (2004). Major Terrorist Events in the U.S. and Their Outcomes: Initial Analysis and Observations. Journal of Homeland Security and Emergency Management, 1(1). doi:10.2202/15477355.1007

Rubin, C. B. (2009). Long Term Recovery from Disasters -- The Neglected Component of Emergency Management. Journal of Homeland Security and Emergency Management, 6(1). doi:10.2202/15477355.1616

Sheridan, J., Chamberlain, K., Dupuis, A. (2011). Timelining: visualizing experience. Qualitative Research, 11(5), 552-569.

Slim, H., Thompson, P. (1993). Listening for a Change: Oral testimony and development. London: Panos Publications.

Smith, G., Birkland, T. (2012). Building a Theory of Recovery: Institutional Dimensions. International Journal of Mass Emergencies and Disasters, 30(2), 147-170.

Sparks, R. S. J., Young, S. R. (2002). The eruption of Soufriere Hills Volcano, Montserrat (1995-1999): overview of scientific results. In T. H. Druitt \& B. P. Kokelaar (Eds.), The eruption of Soufrière Hills Volcano, Montserrat from 1995 to 1999 (Vol. 21, pp. 45-69). London: Geological Society, London, Memoirs 2002.

Stewart, C., Johnston, D., Nathan, S. (2007). When Disaster Strikes: Collected disaster stories (No. 2007/05). Wellington.

Sword-Daniels, V. L. (2011). Exploring long-term volcanic living through social infrastructure systems: consequences, adaptation and developing resilience in Montserrat. Mphil thesis. University College London.

Sword-Daniels, V. L. (2014). Exploring the consequences and dynamics of long-term volcanic activity for the healthcare system in Montserrat, West Indies. EngD thesis. University College London. 
Sword-Daniels, V. L., Twigg, J., Rossetto, T., Johnston, D. M. (n.d., In Review). Unpacking long-term disaster recovery processes: a case study of the healthcare system in Montserrat, West Indies. International Journal of Mass Emergencies and Disasters.

Sword-Daniels, V., Wilson, T. M., Sargeant, S., Rossetto, T., Twigg, J., Johnston, D. M., Loughlin, S. C., Cole, P. D. (2014). Consequences of long-term volcanic activity for essential services in Montserrat: challenges, adaptations and resilience. In G. Wadge, R. E. A. Robertson, \& B. Voight (Eds.), The eruption of Soufrière Hills Volcano, Montserrat from 2000 to 2010 (Vol. 39, pp. 471-488). London: Geological Society of London Memoirs.

Taylor, R., Ward, A., Newburn, T. (Eds.). (1995). The Day of the Hillsborough Disaster: A narrative account. Liverpool: Liverpool University Press.

Thompson, P. (1988). The Voice of the Past: Oral history (2nd ed.). Oxford: Oxford University Press.

Tierney, K., Oliver-Smith, A. (2012). Social dimensions of disaster recovery. International Journal of Mass Emergencies and Disasters, 30(2), 123-146.

United Nations Strategy for International Development (UNISDR). (2009). Terminology on Disaster Risk Reduction (p. 13). Geneva, Switzerland.

Van der Vaart, W., Glasner, T. (2007). Applying a Timeline as a Recall Aid in a Telephone Survey: A Record Check Study y. Applied Cognative Psychology, 21, 227-238. doi:10.1002/acp

Wason, A. T. (1994). Vulnerability survey of health facilities in Montserrat, West Indies (pp. 1-19). Bridgetown, Barbados: Pan American Health Organisation.

Wilson, S., Cunningham-Burley, S., Bancroft, A., Backett-Milburn, K., Masters, H. (2007). Young people, biographical narratives and the life grid: young people's accounts of parental substance use. Qualitative Research, 7(1), 135-151. doi:10.1177/1468794107071427

Wisner, B., Blaikie, P., Cannon, T., Davis, I. (2004). At Risk: natural hazards, people's vulnerability and disasters (p.471). Routledge.

Wolfe, J., Jackson, C. (1987). Creating models of the strategic decision making process via participant recall: a free simulation examination. Journal of Management, 13(1), 123-134.

Worth, N. (2011). Evaluating life maps as a versatile method for lifecourse geographies. Area, 43(4), 405-412. 